\title{
Synthesis of nanosized mordenite with enhanced catalytic performance in the alkylation of benzene with benzyl alcohol
}

Meng-Nan Liu, ${ }^{1}$ Zhi-Xia Xie, ${ }^{1}$ Qun-Xing Luo, ${ }^{1,2,3}$ Jianbo Zhang, ${ }^{1,2,3}$ Huiyong Chen, ${ }^{1,2,3}$ Long Xu, ${ }^{1,2,3}$ Ming Sun, ${ }^{1,2,3}$ Xiaoxun Ma, ${ }^{1,2,3}$ Qing-Qing Hao ${ }^{* 1,2,3}$

${ }^{1}$ School of Chemical Engineering, Northwest University, Xi'an, Shaanxi 710069, China

${ }^{2}$ Chemical Engineering Research Center of the Ministry of Education for Advanced Use Technology of Shanbei Energy, Xi'an, Shaanxi 710069, China

${ }^{3}$ International Science \& Technology Cooperation Base of MOST for Clean Utilization of Hydrocarbon Resources; Collaborative Innovation Center for Development of Energy and Chemical Industry in Northern Shaanxi, Xi'an, Shaanxi 710069, China

*Corresponding author:

Dr. Qing-Qing Hao

Email: haoqq@nwu.edu.cn 


\section{Table of Contents}

Figure S1. The FWHM of (202) with different samples...............................................

Figure S2. SEM images of MOR synthesized under various $\mathrm{Na}_{2} \mathrm{O} / \mathrm{SiO}_{2} \ldots \ldots \ldots \ldots \ldots \ldots . . \mathrm{S} 3$

Figure S3. XRD patterns of MOR synthesized with different mole ratio of $\mathrm{Na}_{2} \mathrm{O} / \mathrm{SiO}_{2}$.

0.1 (a), 0.25 (b), 0.3 (c), 4 days S3

Figure S4. More SEM images of MOR-0.35 S4

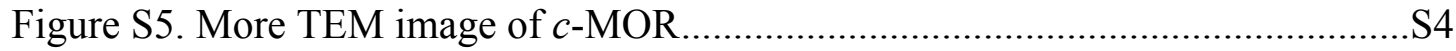

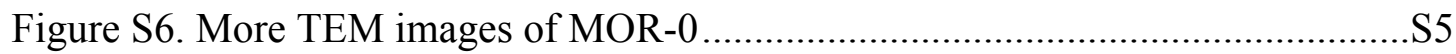

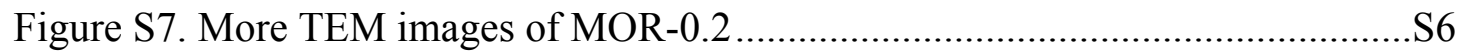

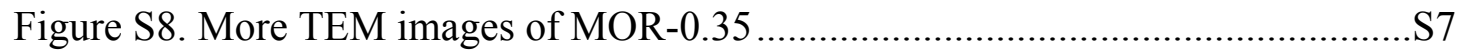

Figure S9. The influence of external diffusion (A) and internal diffusion (B) of MOR-

0 at $85^{\circ} \mathrm{C}$. S7

Figure S10. The pseudo-first order rate law of $\ln (1 /(1-\mathrm{x}))$ as a function of (Time) over MOR-0 zeolite with different reaction temperature. $363 \mathrm{~K}$, (A); $358 \mathrm{~K}$, (B); $353 \mathrm{~K}$, (C); $348 \mathrm{~K},(\mathrm{D})$. S8

Table S1. The micropore volume of MORs in our work and nanosized MORs reported in the literatures..... S9

Table S2. $\mathrm{pH}$ values of different initial synthesis gel S9

References S10 


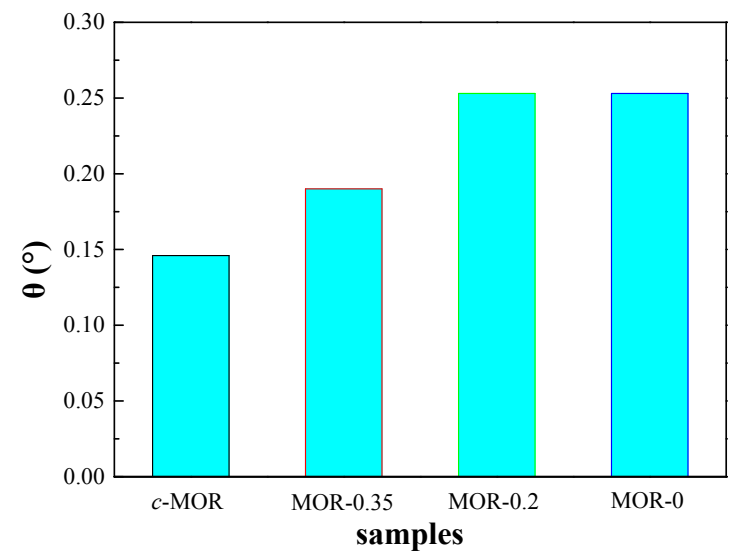

Figure S1. The FWHM of (202) with different samples

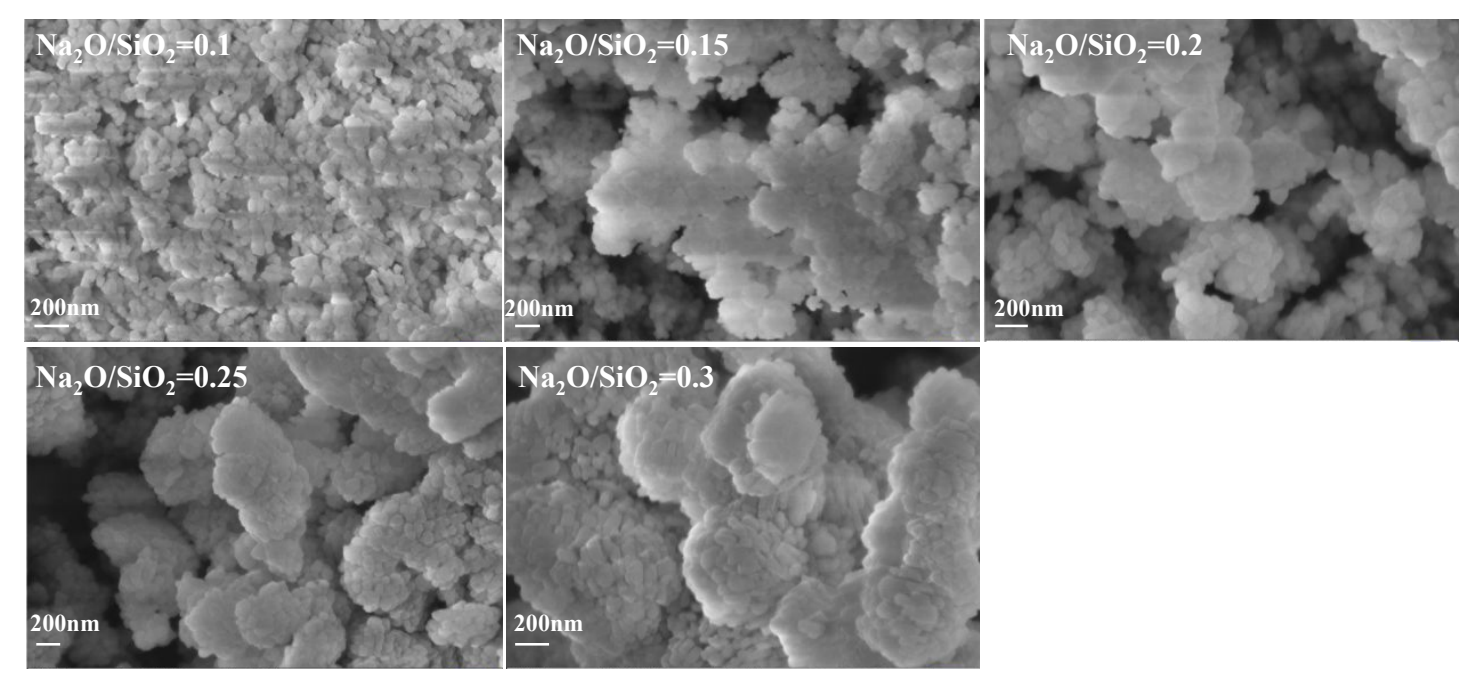

Figure S2. SEM images of MOR synthesized under various $\mathrm{Na}_{2} \mathrm{O} / \mathrm{SiO}_{2}$.

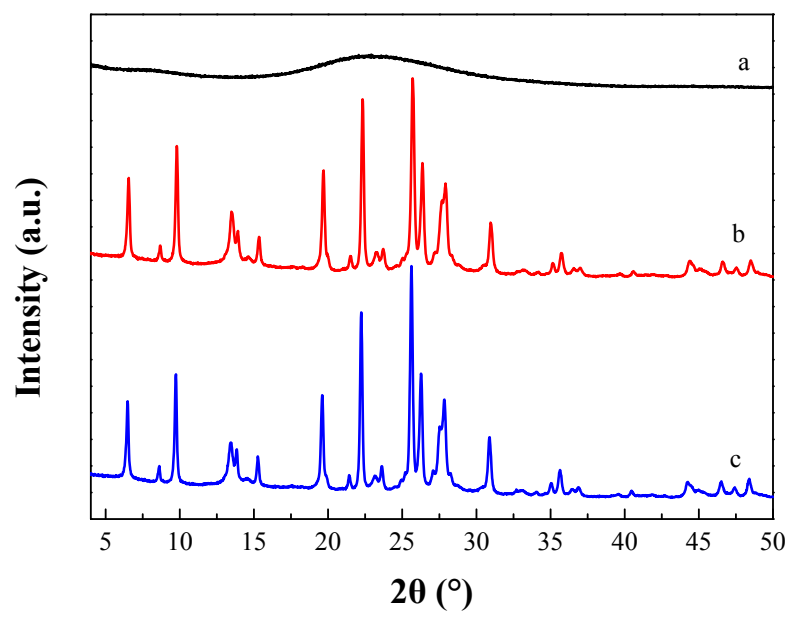

Figure S3. XRD patterns of MOR synthesized with different mole ratio of $\mathrm{Na}_{2} \mathrm{O} / \mathrm{SiO}_{2}$. 0.1 (a), 0.25 (b), 0.3 (c), 4 days. 


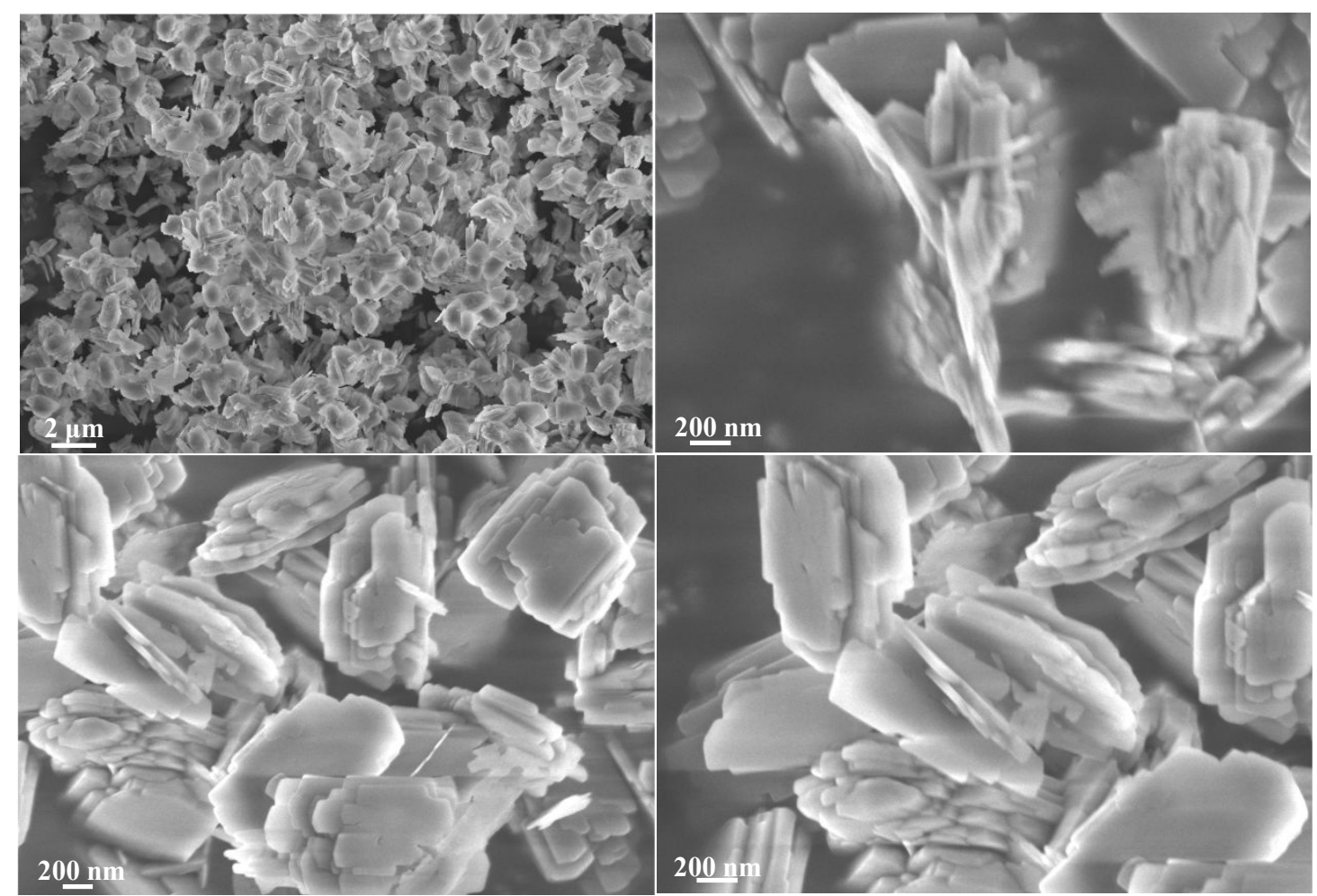

Figure S4. More SEM images of MOR-0.35

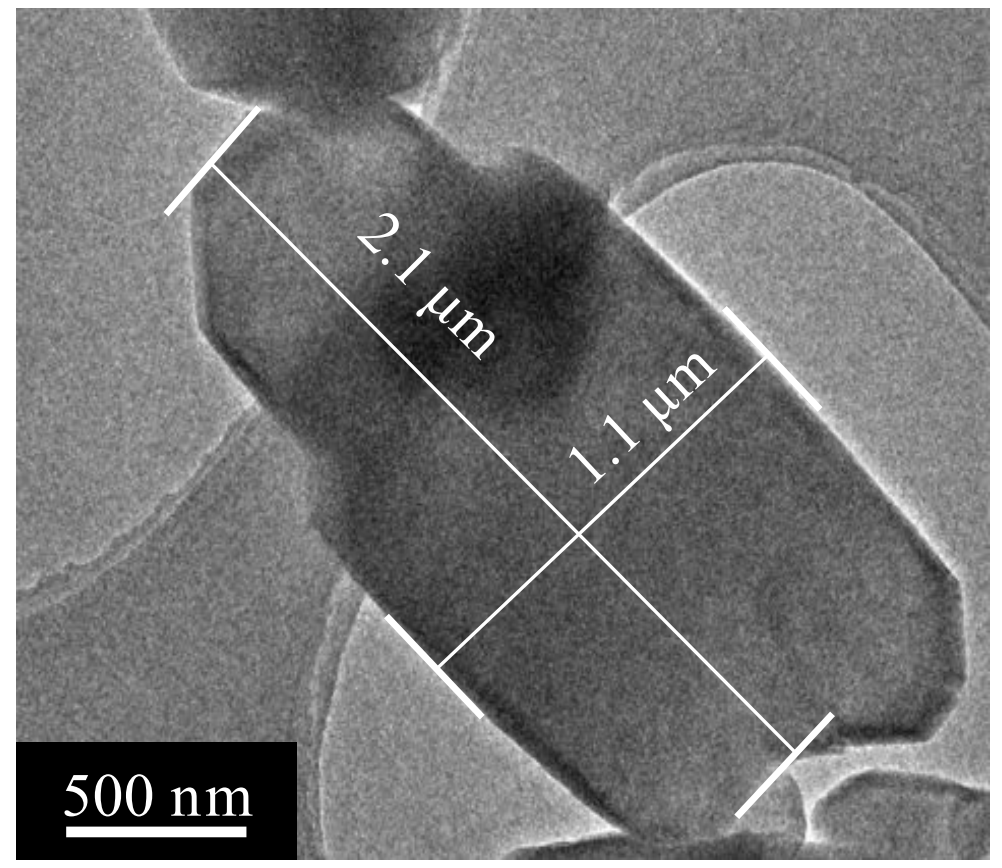

Figure S5. More TEM image of $c$-MOR 


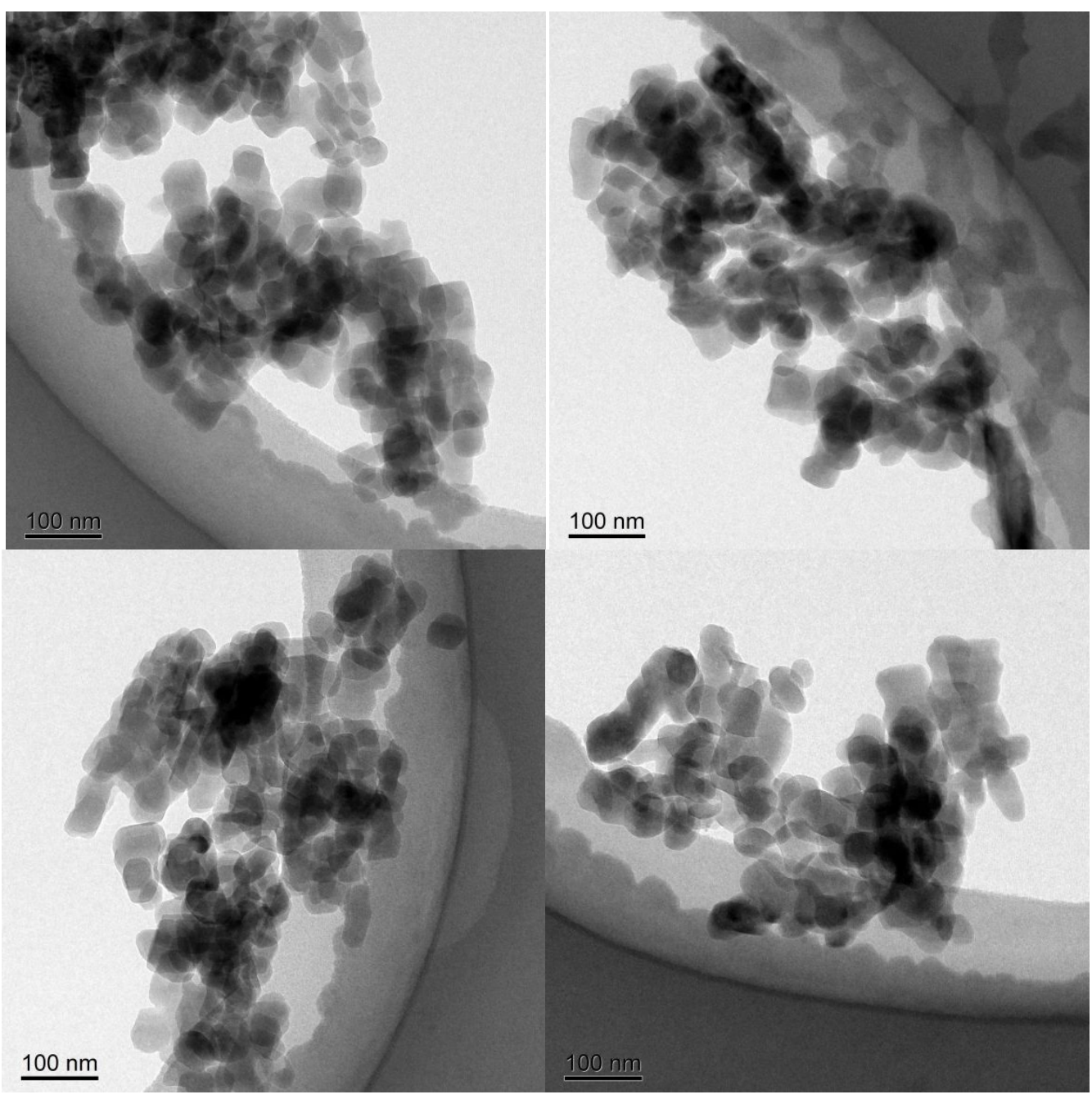

Figure S6. More TEM images of MOR-0 


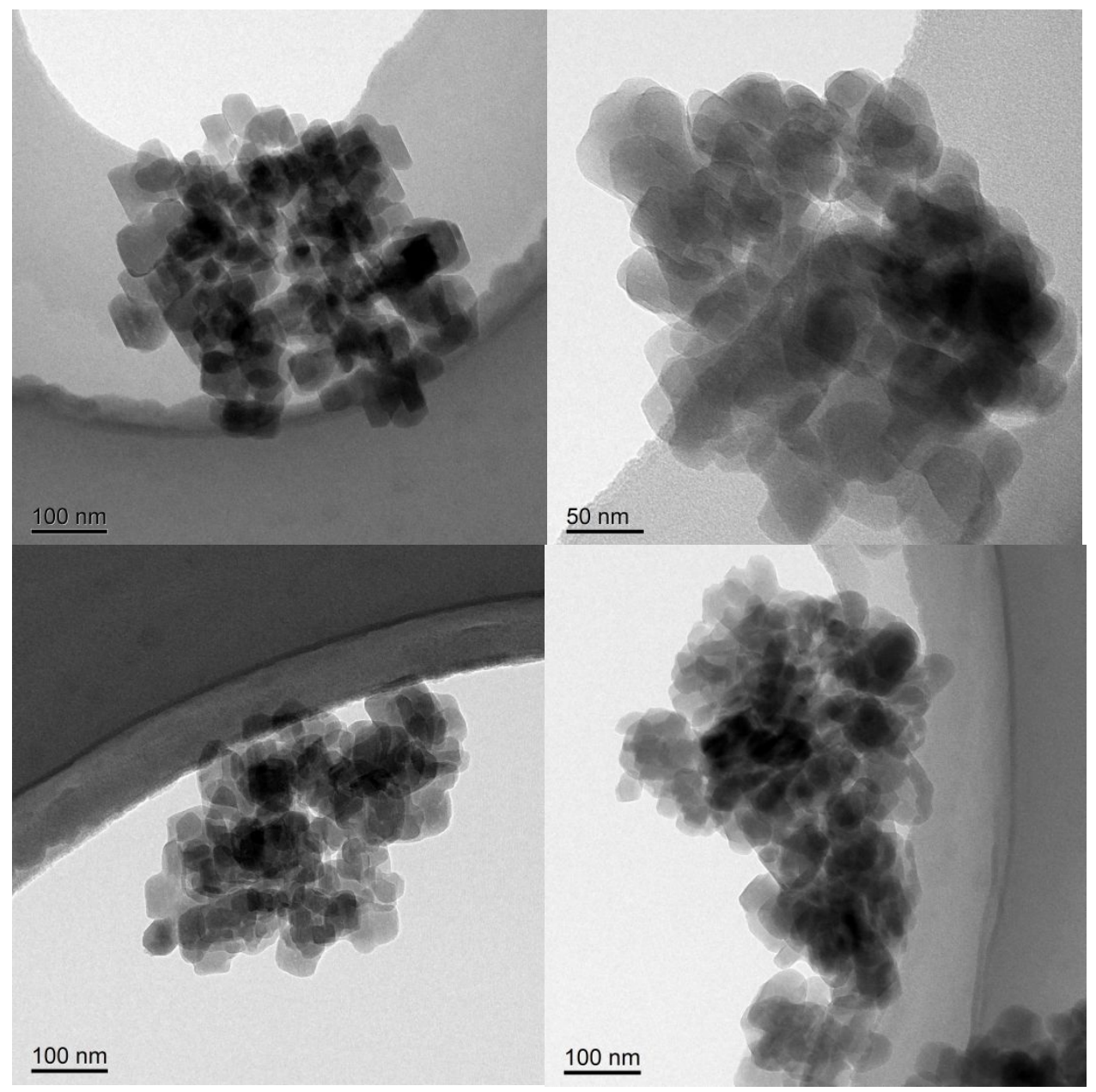

Figure S7. More TEM images of MOR-0.2 


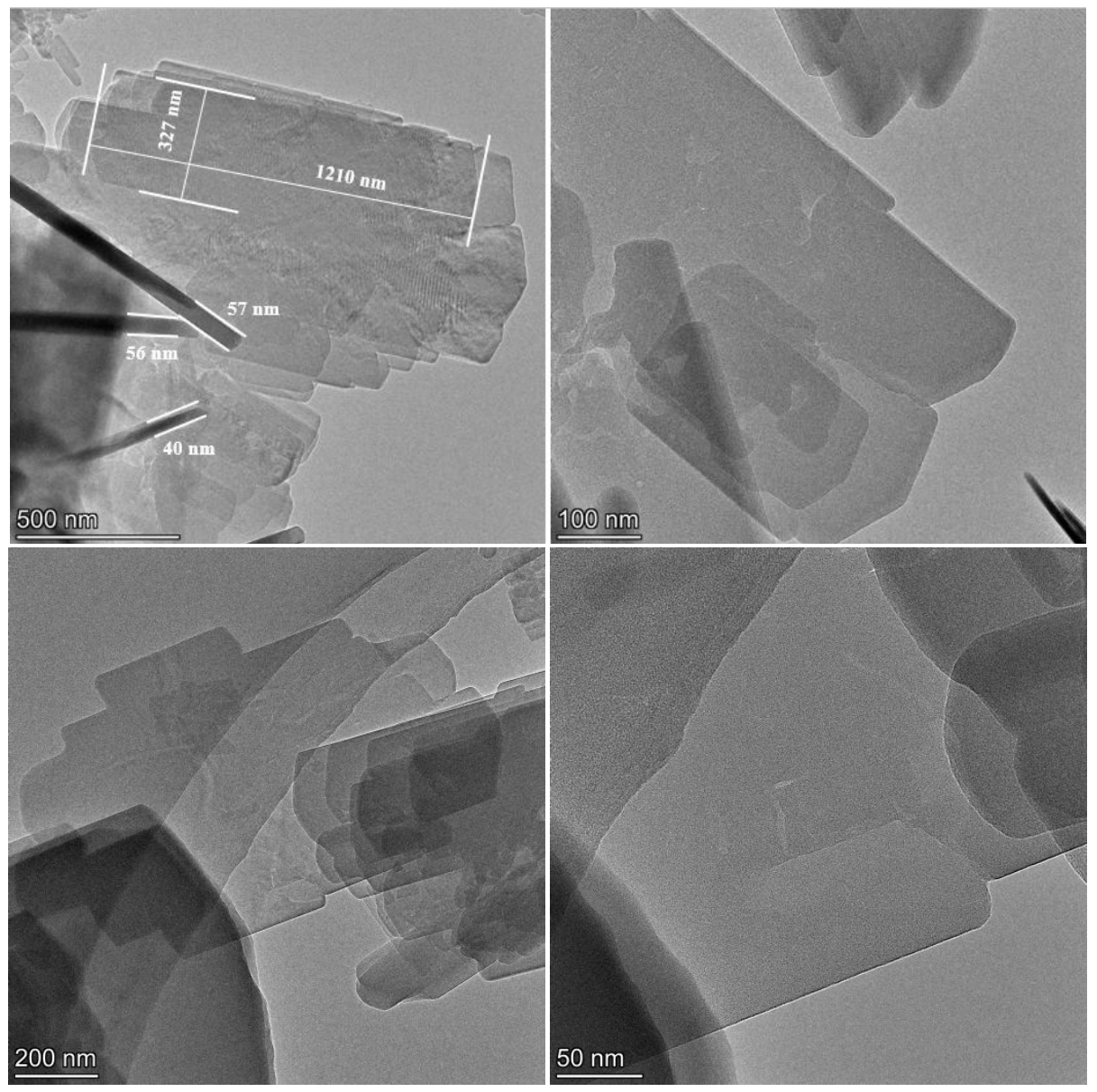

Figure S8. More TEM images of MOR-0.35
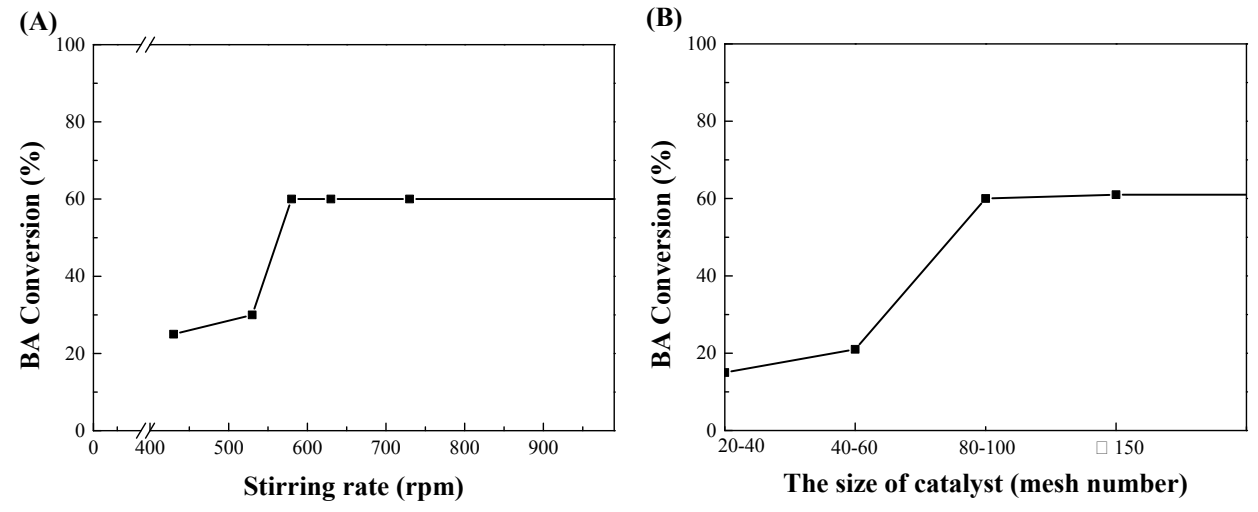

Figure S9. The influence of external diffusion (A) and internal diffusion (B) of MOR0 at $85^{\circ} \mathrm{C}$ 

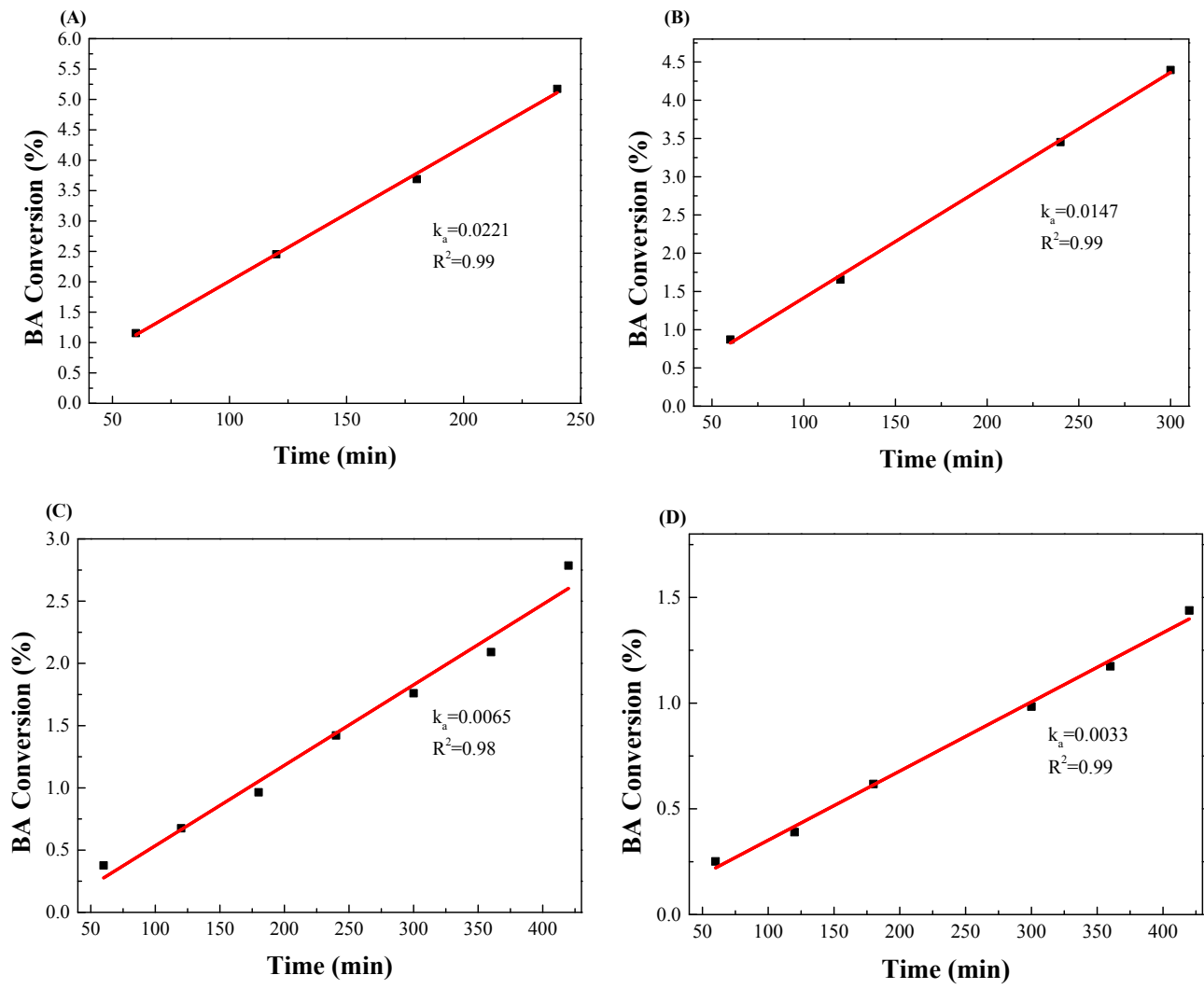

Figure S10. The pseudo-first order rate law of $\ln (1 /(1-\mathrm{x}))$ as a function of (Time)

over MOR-0 zeolite with different reaction temperature. $363 \mathrm{~K}$, (A); $358 \mathrm{~K}$, (B); 353

$\mathrm{K},(\mathrm{C}) ; 348 \mathrm{~K},(\mathrm{D})$. 
Table S1. The micropore volume of MORs in our work and nanosized MORs reported in the literatures

\begin{tabular}{c|c}
\hline Sample & Micropore volume \\
MOR-0 & 0.19 \\
MOR-0.2 & 0.18 \\
MOR-0.35 & 0.18 \\
HMOR $^{1}$ & 0.195 \\
MOR-M $^{2}$ & 0.17 \\
\hline
\end{tabular}

Table S2. $\mathrm{pH}$ values of different initial synthesis gel

\begin{tabular}{c|c}
\hline Sample & $\mathrm{pH}$ \\
\hline MOR-0 & 13.23 \\
MOR-0.2 & 13.30 \\
MOR-0.35 & 13.35 \\
\hline
\end{tabular}




\section{References}

(1) Xue, H. F.; Huang, X. M.; Ditzel, E.; Zhan, E. S.; Ma, M.; Shen, W. J. Dimethyl Ether Carbonylation to Methyl Acetate over Nanosized Mordenite. Ind. Eng. Chem. Res.,2013, 52, 11510-11515.

(2) Yuan, Y. Y.; Wang, L. Y.; Liu, H. C.; Tian, P.; Yang, M.; Xu, S. T.; Liu, Z. M. Facile preparation of nanocrystal-assembled hierarchical mordenite zeolites with remarkable catalytic performance. Chinese J. Catal., 2015, 36, 1910-1919. 